\title{
FERNANDO IWASAKI, UN ENSAYISTA DEL BICENTENARIO
}

\author{
Fernando Iwasaki, an essayist of bicentenary
}

\author{
Rosa Núñez Pacheco ${ }^{1}$
}

\begin{abstract}
RESUMEN
Este artículo aborda desde la perspectiva del análisis del discurso uno de los géneros que ha adquirido mucha relevancia en América Latina como es el caso del ensayo; es decir, es un análisis del discurso ensayístico, yen particular de un conjunto de ensayos que abordan temas de carácter histórico, cultural y político, dentro del contexto del Bicentenario de las Independencias de los países hispanoamericanos. Se trata del libro Republicanos, cuando dejamos de ser realistas (2008) del escritor peruano Fernando Iwasaki Cauti. A través del análisis discursivo de estos ensayos se establece relaciones intertextuales entre la historia y la literatura.
\end{abstract}

Palabras clave: Ensayo latinoamericano, Bicentenario, Fernando Iwasaki, Ironía.

\begin{abstract}
This article discusses the perspective of discourse analysis, one of the genres that has become very important in Latin America. As in the case of the essay; that is to say, it is an analysis of essayistic discourse, and especially a collection of essays that address issues of historical, cultural and political kind, within the context of the Bicentennial of the Independence of the Latin American countries. This is the book Republicans, When We Stop Being Realistic (2008) by the peruvian writer Fernando Iwasaki Cauti. Through discoursive analysis of these trials, inter textual relations between history and literature are established.
\end{abstract}

Keywords: Latin American Essay, Bicentennial, Fernando Iwasaki, Irony.

\section{INTRODUCCIÓN}

El Bicentenario de las Independencias de América Latina ha motivado que se publiquen una serie de textos, en particular ensayos, que reflexionan sobre este importante momento para nuestras naciones. El libro de ensayos Republicanos, cuando dejamos de ser realistas (2008) de Fernando Iwasaki justamente reflexiona críticamente sobre este trascendental momento histórico y tiene la particularidad de conjuncionar dos discursos: la historia y la literatura, los cuales entran en diálogo fructífero y gratificante en la pluma del autor peruano.

El objetivo general de esta investigación es analizar discursivamente el tema del Bicentenario de América Latina en el libro Republicanos, cuando dejamos de ser realistas de Fernando Iwasaki; y los objetivos específicos corresponden al análisis desde el punto de vista sintáctico, semántico, verbal, pragmático y crítico de dicho libro de ensayos, y además

\footnotetext{
${ }^{1}$ Docente del Departamento Académico de Literatura y Lingüistica de la Universidad Nacional de San Agustín. Arequipa-Perú.

Correoelectrónico:rnp100@yahoo.com
} 
sintáctico, semántico, verbal, pragmático y crítico de dicho libro de ensayos, y además establecer las relaciones intertextuales entre el discurso histórico y literario en el ensayo hispanoamericano del Bicentenario.

Las principales preguntas que guían este trabajo son: ¿cómo se aborda el tema del Bicentenario en el libro de ensayos Republicanos, cuando dejamos de ser realistas de Fernando Iwasaki? y ¿cómo se entrecruzan los discursos histórico y literario en esos ensayos?

La metodología utilizada es propia del análisis del discurso, que por su carácter interdisciplinario permite abordar diversos campos de estudio como en este caso la historia y la literatura. María Elena Arenas, cuyo trabajo titulado Hacia una teoría general del ensayo. Construcción del texto ensayístico (1997), recoge principalmente los aportes de la pragmática, la lingüística del texto y la semiótica, los cuales han sido sistematizados en dos dimensiones: el macrocomponente sintáctico-semántico y el microcomponente verbal; y la dimensión pragmática que tiene que ver con el contexto. Estos mismos niveles de análisis discursivo han sido aplicados al texto de Fernando Iwasaki.

\section{LOS ENSAYOS DEL BICENTENARIO}

Entre los años 2009 y 2011 alrededor de diez países latinoamericanos conmemoraron el Bicentenario de sus Independencias. En 2009, Bolivia y Ecuador; en 2010, Argentina, Chile, Colombia, México y Venezuela; en 2011, Uruguay, Paraguay y El Salvador. Algunos de ellos acomodaron la fecha para festejar ese momento como es el caso de Uruguay que dictó una ley especial y el de Bolivia, que adelantó los festejos al año 2009. El Perú recién lo hará el año 2021.

La conmemoración del Bicentena- rio de las Independencias ha motivado que se escriban y publiquen una serie de ensayos en torno al tema. Desde una mirada interdisciplinaria se reflexiona sobre ese proceso histórico lo cual ha conllevado a los intelectuales a una postura crítica sobre la situación y destino de los países latinoamericanos. En los últimos diez años han aparecido, pues, diversos tipos de textos entre los cuales destacan los ensayos que si bien abordan el tema histórico del Bicentenario lo hacen generalmente recurriendo a los procedimientos literarios, lo cual demuestra que la historia y la literatura en estos albores del siglo XXI han reforzado sus vínculos disciplinares.

A continuación señalaremos algunos libros de ensayos que se han publicado en nuestro ámbito latinoamericano a propósito del Bicentenario: Martín Kohan: Narrar a San Martín (2005); Jaime E. Rodríguez: La independencia de la América española (2005); Fernando Iwasaki: rePLBLICANOS, cuando dejamos de ser realistas (2008); Jorge Volpi: El insomnio de Bolivar: cuatro consideraciones intempestivas sobre América Latina en el siglo XXI, (2009); Rafael Rojas: Las repúblicas de aire. Utopía y desencanto en la Revolución de Hispanoamérica (2009); John Lynch: San Martín. Soldado argentino, héroe americano (2009); Manuel Lucena Giraldo: Naciones rebeldes. Las revoluciones de independencia latinoamericanas (2010); Tomás Pérez Vejo: Elegía criolla.Una reinterpretación de las guerras de independencia hispanoamericanas (2010); Hugo Neira: Las independencias. Doce ensayos (2010); Ignacio Padilla: La isla de las tribus perdidas. La incógnita del mar latinoamericano (2010); Felipe Pigna: Libertadores de América. Vida y obra de nuestros revolucionarios (2010); Enrique Krauze: Redentores. Ideas y poder en América Latina (2011); Guzmán Carriquiry: El Bicentenario de la Independencia de los paí- 
ses latinoamericanos (2011), entre otros.

\section{FERNANDO IWASAKI Y SUS ENSAYOS DEL BICENTENARIO}

Fernando Iwasaki Cauti es autor de muchos libros de relatos y novelas como Neguijón (2005) y Libro de mal amor (2001); ensayos literarios como Nabokovia Peruviana (2011), Mi poncho es un kimono flamenco (2005) y El descubrimiento de España (1996). Dentro de este último grupo, por el estilo que emplea, se puede incluir a rePUBLICANOS, cuando dejamos de ser realistas (2008), sin embargo este libro también corresponde al terreno de la historia, como sus otros libros Nación peruana: entelequia o utopía. Trayectoria de una falacia (1988) y Extremo Oriente y el Perú en el siglo XVI (2005). Por su misma formación profesional que es la de historiador, Fernando Iwasaki recurre a esta disciplina para realizar sus investigaciones, pero al mismo tiempo le sirve para sumergirse en el mundo literario. De ahí que varios de sus relatos tienen una base histórica, o viceversa, muchos de sus ensayos históricos tienen un vínculo con la literatura, como es el caso de Republicanos, cuando dejamos de ser realistas (2008), libro ganador del premio Algaba en España.

Este libro está conformado por doce capítulos. En realidad cada capítulo puede constituirse como un ensayo independiente, para los cuales utilizaremos una simbología a lo largo del análisis: "Una modernidad a la antigua" (E1), "A oscuras en el siglo de las luces" (E2), "La tentación mercantilista" (E3), "Fernando VII nunca descubrió América" (E4), "1812: Constitución original y pecado constitucional" (E5), "Bolívar 5 - San Martín 3" (E6), "Caudillos, comandantes y generalísimos" (E7), "Herejes, blasfemos y arrepticios" (E8), "Alegría, melancolía y cursilería" (E9), "El huevo y la gallina o la identidad y la independencia" (E10), "Revolucionarios orteguianos -unamunescos" (E11), "Pre boom, proto boom y pos boom" (E12). A continuación realizaremos el análisis discursivo a través de los niveles semántico, sintáctico, verbal, pragmático y crítico dealgunos de estos ensayos.

\section{Niveles semántico y sintáctico "Una modernidad a la antigua" (E1)}

Este ensayo gira en torno al tema de la premodernidad de España y de sus excolonias. Iwasaki plantea como tesis que España no fue una nación moderna y sus antiguas colonias una vez independizadas "tampoco podían ser modernas, porque nacieron como países independientes a imagen y semejanza de su vieja metrópoli" (pp. 26-27).

Para Iwasaki, la modernidad occidental encuentra sus fundamentos entre los siglos XV y XVIII, y habría cuatro elementos que contribuyeron a transformar a los grandes estados europeos. Estos elementos fueron: "el desmoronamiento del feudalismo, la Reforma o disidencia religiosa, la revolución industrial y la revolución cultural e ideológi-

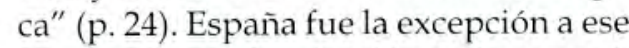
proceso de modernización de Europa. A diferencia de los otros países europeos, España no tuvo una etapa feudal debido a que durante ocho siglos sufrió la invasión musulmana, de modo que para su expulsión la Corona tuvo que estrechar lazos con la nobleza y el pueblo cristianos. Tampoco permitió que la Reforma se desarrollara en su territorio, al contrario promovió la Contrarreforma e impidió que se difundiera el humanismo erasmista que hubiera permitido un florecimiento espiritual y no un fundamentalismo alentado por la Inquisición española. Asimismo, España no participó de la revolución industrial la cual 
hubiera impedido que siga siendo hasta inicios del siglo XX "un país tan centralista, preindustrial y agropecuario" (pp. 25-26); tampoco acató la revolución cultural e ideológica que traía consigo la Constitución de 1812.

Según Iwasaki, este último elemento referido a las Cortes de Cádiz y la Constitución de 1812 es fundamental para comprender la falta de modernidad en la historia novecentista de España y América Latina, porque si se hubiera acatado dicha Constitución se habría establecido un respeto a la legalidad y las instituciones democráticas, también se hubiera forjado una concepción laica del Estado y de la enseñanza pública, se hubiera instituido una defensa de los derechos de los ciudadanos, así como una idea positiva del trabajo y la riqueza como agentes de prosperidad social e individual (p. 29).

Finalmente, Iwasaki concluye su ensayo señalando que lo más grave es que para nuestra precaria modernidad igualdad y libertad resulten incompatibles, lo cual ha conllevado a convertirnos en sociedades cerradas que no respetan al individuo. El autor cree que:

La modernidad occidental surgió gracias al descubrimiento del individuo. [...] Ni España ni las nuevas repúblicas hispanoamericanas asimilaron el individualismo más allá de la retórica política y de la sintaxis constitucional, y por eso nuestra modernidad fue más bien a la antigua, porque en lugar de una soberanía individual que propiciara la libertad y fomentara sociedades abiertas, preferimos una soberanía tribal, corporativa, estamental, que en nombre de la igualdad nos condenó al narcisismo botarate de las sociedades cerradas (p.30).
Podemos esquematizar estos elementos semánticos y sintácticos constitutivos del género ensayístico en los siguientes esquemas (Ver tablas 1, 2 y 3 , y figuras 1,2 y 3 )

\section{"Fernando VII nunca descubrió Améri- ca" (E4)}

El tema que plantea en este ensayo gira en torno al desconocimiento de los gobernantes españoles sobre la riqueza natural y cultural de América. Iwasaki sostiene que solo una minoría de burócratas y funcionarios españoles tuvo verdadera conciencia de la existencia del imperio colonial (p. 58).

Para Iwasaki, el rey Fernando VII probablemente no tenía una clara conciencia de la existencia de sus colonias, por ello, cuando Napoleón Bonaparte invadió España en 1807 y coronó a su hermano José Bonaparte luego de las abdicaciones de los monarcas españoles, Fernando VII prefirió refugiarse en Bayona antes que en sus propias colonias, mientras que el rey de Portugal, Juan VI, sí se refugió en sus dominios del Brasil hasta 1820 junto a su esposa Carlota Joaquina de Borbón (p. 57). Lo mismo pasaría, según el autor, con la mayoría de españoles de principios del siglo XIX, ya que "solo una minoría de burócratas y funcionarios tuvo conciencia de la existencia del imperio colonial" (p. 58). Prueba de ello sería el destino que tuvieron los informes y estudios que encargaron los ministros como Aranda, Campomanes, Floridablanca y Godoy a eminentes científicos durante el siglo XVIII, los cuales habrían terminado sepultados en "archivos, bibliotecas y otros mausoleos de la Ilustración española" (p. 58) y es probable que los reyes no los hayan leído. Sus argumentos se basan principalmente en la indiferencia de los monarcas borbones a las misiones científicas de Antonio de Ulloa y Jorge Juan y Santaci- 
Tabla 1. E1: La premodernidad de España y de sus excolonias

\begin{tabular}{|c|c|c|c|}
\hline N. & TEMA & TESIS & TÓPICOS ARGUMENTATIVOS \\
\hline$\overline{\mathrm{E} 1}$ & $\begin{array}{l}\text { La premodernidad } \\
\text { de España y de sus } \\
\text { excolonias }\end{array}$ & $\begin{array}{l}\text { España no fue una nación moderna y } \\
\text { sus antiguas colonias una vez inde- } \\
\text { pendizadas "tampoco podian ser } \\
\text { modernas, porque nacieron como } \\
\text { países independientes a imagen y } \\
\text { semejanza de su vieja metrópoli" }[8]^{*}\end{array}$ & $\begin{array}{l}\text { - Fundamentos de la modernidad occi- } \\
\text { dental: el desmoronamiento del feuda- } \\
\text { lismo, la Reforma o disidencia religiosa, } \\
\text { la revolución industrial y la revolución } \\
\text { cultural e ideológica.[4 al 7]. } \\
\text { - Similitud de las historias políticas entre } \\
\text { España y América Latina [9-10-11] } \\
\text { - Incipiente industrialización [12] } \\
\text { - Falta de respeto a la legalidad e institu- } \\
\text { ciones democráticas [13-14] } \\
\text { - Sociedades cerradas: desplazamiento } \\
\text { del individuo [14-15] }\end{array}$ \\
\hline
\end{tabular}

(*Para el análisis semántico y sintáctico de los ensayos indicaremos el número de párrafo del ensayo entre corchetes.)

\section{Superestructura argumentativa}

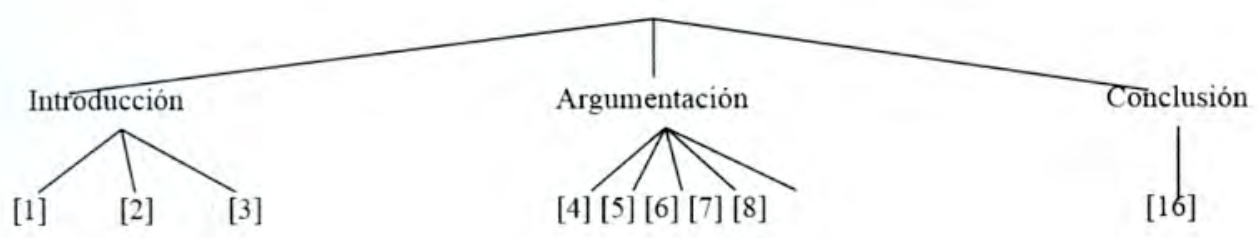

[9]

[13]

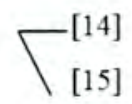

Figura 1. E1: La premodernidad de España y de sus excolonias

lia (1735-1745), y del italiano Alejandro Malaspina (1789-1794). De igual forma para fundamentar su idea sobre la falta de una clara conciencia de la existencia de las colonias en el pueblo español, Iwasaki analiza la presencia de América en el habla y en los hábitos alimenticios de la España del siglo XVIII.

Iwasaki concluye su ensayo afirmando que durante los tres siglos de dominación colonial, "la única conciencia que los reyes y aristócratas españoles tuvieron de América se limitó a los meta- les preciosos y a unos cuantos artículos suntuarios como las joyas, ciertas maderas finas y algún que otro capricho gastronómico como el chocolate" (p.66).

\section{"Bolívar 5 - San Martín 3" (E6)}

El tema que aborda Iwasaki en este ensayo gira en relación a los proyectos políticos de los dos libertadores de América como son José de San Martín y Simón Bolívar. El autor sostiene que "San Martín se dejó arrebatar la gloria de la independencia, porque juzgó innece- 
Tabla 2. E4: El desconocimiento de la riqueza natural de América.

\begin{tabular}{|c|c|c|c|}
\hline & TEMA & TESIS & TÓPICOS ARGUMENTATIVOS \\
\hline $\mathrm{E} 4$ & $\begin{array}{l}\text { El desconocimiento de } \\
\text { la riqueza natural de } \\
\text { América }\end{array}$ & $\begin{array}{l}\text { Solo una minoría de burócratas y } \\
\text { funcionarios españoles tuvo verda- } \\
\text { dera conciencia de la existencia del } \\
\text { imperio colonial [2]. }\end{array}$ & $\begin{array}{l}\text { - Refugio de Fernando VII en Bayona y } \\
\text { no en sus colonias } \\
\text { - Poca importancia a informes e estu- } \\
\text { dios realizados por científicos duran- } \\
\text { te el siglo XVIII [3-4] } \\
\text { - Expediciones científicas de Antonio } \\
\text { de Ulloa, Jorge Juan Santacilia y } \\
\text { Alejandro Malaspina [5a 12] } \\
\text { - Palabras nuevas provenientes de } \\
\text { América [13-14]. } \\
\text { - Nuevos hábitos alimenticios [15a 21] }\end{array}$ \\
\hline
\end{tabular}

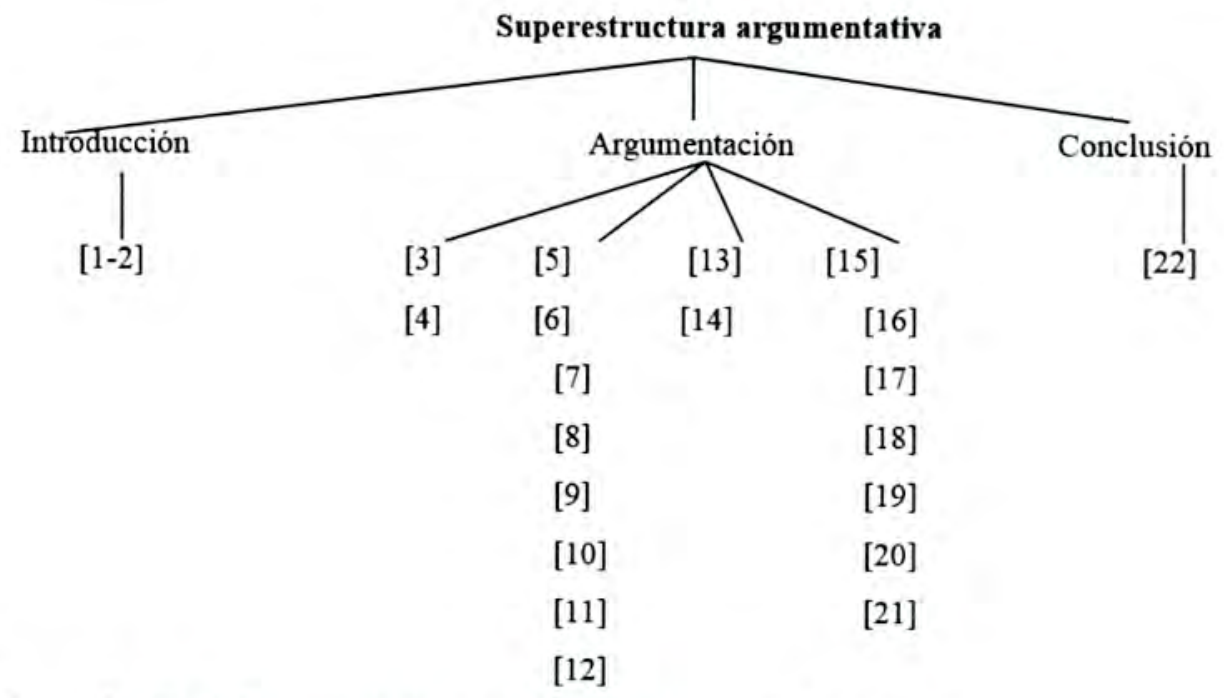

Figura 2. E4: El desconocimiento de la riqueza natural de América.

sario acreditar su valía o porque comprendió que semejante empresa suponía una voluntad como la de Bolívar" (p. 85).

Haciendo referencia al cuento de Borges titulado "Guayaquil", Iwasaki hace una comparación entre las figuras de los dos personajes centrales de la independencia latinoamericana: Don José de San Martín y don Simón Bolívar. Cuando ambos libertadores se encontraron en Guayaquil, se vio que ambos poseían proyectos políticos distintos: "San Martín creía que la monarquía constitucional podía ser un sistema de gobierno eficaz para los nuevos países independientes
[...] Bolívar -por su parte- creía en un sistema republicano y parlamentario de supuesta ideología progresista y liberal, aunque nada más arribar al Perú sus primeras decisiones fueron dos medidas retrógradas" (pp.87-88).

Iwasaki agrega además que "en Guayaquil se enfrentaron los dos modelos seculares e incompatibles de la política latinoamericana: el caudillo carismático, ambicioso y autoritario que se ve a sí mismo como salvador de la patria, y el hombre con sentido de estado que subordina sus aspiraciones personales en aras de la legalidad y la convivencia 
Tabla 3. E6: Los proyectos políticos de José de San Martín y Simón Bolívar.

\begin{tabular}{|c|c|c|c|}
\hline$\overline{\mathrm{N}}$. & TEMA & TESIS & TÓPICOS ARGUMENTATIVOS \\
\hline$\overline{\mathrm{E} 6}$ & $\begin{array}{l}\text { Los proyectos políti- } \\
\text { cos de José de San } \\
\text { Martín y Simón Bolí- } \\
\text { var }\end{array}$ & $\begin{array}{l}\text { San Martín se dejó arrebatar la } \\
\text { gloria de la independencia por } \\
\text { Simón Bolívar. }\end{array}$ & $\begin{array}{l}\text { - Encuentro de José de San Martín y Simón } \\
\text { Bolívar en Guayaquil [2 a 5,12] } \\
\text { - Proyectos políticos de San Martín y Bolí- } \\
\text { var [6-7] } \\
\text { - Supervivencia del caudillismo en Améri- } \\
\text { ca Latina [8 a 11] }\end{array}$ \\
\hline
\end{tabular}

\section{Superestructura argumentativa}

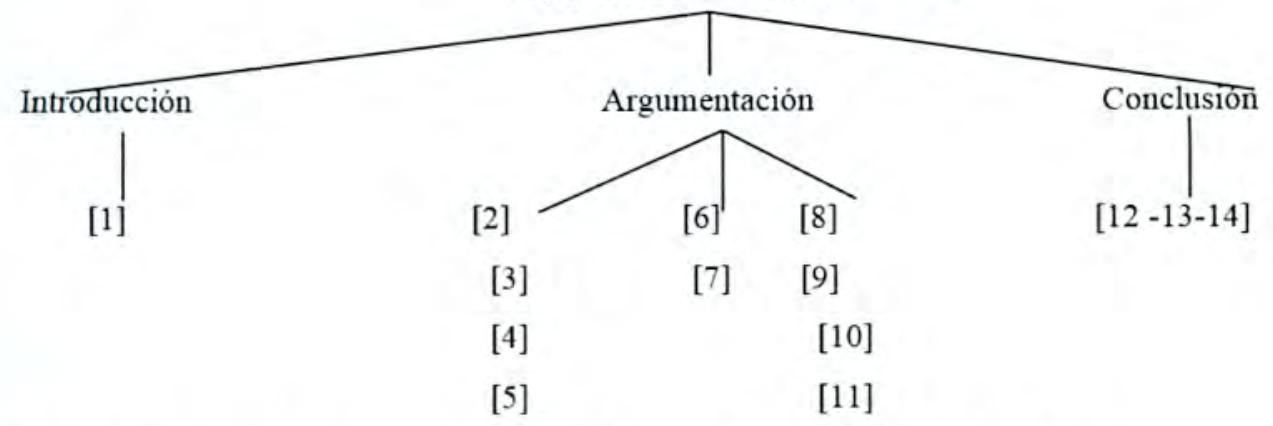

Figura 3. E6: Los proyectos políticos de José de San Martín y Simón Bolívar.

pacífica" (p. 89). A pesar de ello, la historia ha favorecido más la figura de Bolívar que la de San Martín, ya que aún pervive la «utopía bolivariana» en personajes como Fidel Castro y Hugo Chávez.

El ensayista concluye que "la entrevista de Guayaquil tiene más valor simbólico que estratégico, pues el desenlace siempre habría sido el mismo en cualquier circunstancia o lugar. [...] En Guayaquil no hubo ni un vencedor ni un vencido, pero después de Guayaquil -es decir, a lo largo de toda la historia independiente de América Latina- los bolívares siempre han vencido a los sanmartines" (p.91).

\section{Nivel verbal o retórico}

En este nivel, se considera principalmente el análisis del estilo, es decir, el registro o modo expresivo básico en función de las exigencias internas del decoro. En el caso de los ensayos de Fer- nando Iwasaki, una de las figuras que más resalta en sus textos es la ironía.

La ironía es una de las estrategias retóricas que está vinculada a la risa y el humor, aunque haya diferencias entre estas. Sophie Van Den Broeck, citando a Schoentjes, dice "el humor se vincula con la risa y la diversión, o sea con actividades más bien incontrolables, afectivas y directas, la ironía apela a través de la sonrisa al intelecto en un proceso de interrogación dialéctica" (2010, p. 5). La misma autora señala que justamente Fernando Iwasaki se caracteriza porque es uno de los pocos autores latinoamericanos que unen la inteligencia con el humor.

Para el análisis del nivel verbal de los ensayos de Iwasaki, tenemos que distinguir los paratextos del libro y los ensayos propiamente dichos, dejaremos de lado las sugerentes imágenes que acompañan al libro, las cuales pueden ser motivo de un análisis visual aparte. 
Tomaremos en cuenta los títulos, epígrafes, citas, notas al pie de página, prólogo y epílogo. Veamos ambos aspectos:

En relación a los paratextos del libro, podemos decir que en general, el conjunto de ensayos posee un tono literario, por ello el autor se toma la licencia de abordar el tema "con algo de ironía e irreverencia" (p. 19), lo cual se refleja desde el mismo título general del libro y de cada de los ensayos incluidos. Así en el título general del libro rePUBLICANOS, CUANDO DEJAMOS DE Ser REALISTAS, tenemos que, por un lado, la palabra "republicanos" alude al afán de los países hispánicos de convertirse en 'publicanos', es decir, recaudadores de impuestos más que en estados 'republicanos' o verdaderas democracias (p. 54). Por otro lado, la expresión "cuando dejamos de ser realistas" se refiere a la falta de realismo en nuestras acciones las cuales se configuran más como empresas utópicas. Incluso en las páginas iniciales del libro, Iwasaki incluye la definición de las dos palabras, según la RALE, pero agrega una quinta acepción para "republicano", el mismo que le da el sentido irónico, ya que "publicano" significa "persona encargada de recaudar las rentas públicas":

republicano, na. Adj. Perteneneciente o relativo a la república, forma de gobierno. || 2 . Se dice del ciudadano de una república. 113 . Partidario de este género de gobierno. || 4. Buen partido. || 5. Publicano reincidente.

realista. Adj. Partidario del realismo. || 2. Perteneciente o relativo al realismo o a los realistas. Sistema, escuela REALISTA. II 3.Que actúa con sentido práctico o trata de ajustarse a la realidad (p. 13).

Este paratexto rePUBLICANOS, CUANDO DEJAMOS DE Ser
REALISTAS aparece en la portada del libro con los colores rojo y blanco, representando la bandera peruana, y con una tipografía especial que juega con las letras mayúsculas y minúsculas, e igualmente tiene una intención irónica pero a la vez un homenaje crítico a las repúblicas hispanoamericanas y especialmente peruana.

Los títulos de cada uno de los ensayos no dejan también de provocar una sonrisa cómplice en el lector, como por ejemplo los ensayos titulados "A oscuras en el siglo de las luces" en el que se presenta un oxímoron a partir de los elementos oscuro/luz; lo mismo sucede en el título del ensayo "Una modernidad a la antigua" a través de la paradoja modernidad/antigüedad; "1812: Constitución original y pecado constitucional" donde el juego palábrico nos da una connotación jurídico-religiosa; también el ensayo "Bolívar 5 - San Martín 3" que a primera vista pareciera aludir a los resultados de un típico partido de fútbol y no al paralelo que establece entre los dos libertadores. Los otros títulos también tienen peculiaridades estilísticas, así los ensayos "Caudillos, comandantes y generalísimos", "Herejes, blasfemos y arrepticios", "Alegría, melancolía y cursilería" y "Preboom, protoboom y posboom", están organizados en grupos de tres palabras que de manera irónica hacen referencia a distintas situaciones.

Asimismo, los epígrafes que incluye el autor al inicio del libro y de cada uno de los ensayos son importantes. Estos epígrafes corresponden a autores que provienen de distintos campos como la literatura, la historia, la filosofía. Ellos son: Unamuno, Voltaire, Octavio Paz, el conde de Aranda, Julio Camba, Jorge Luis Borges, Sthendal, Julio Caro Baroja, Agustín de Foxá, Julio Cortázar, José Carlos Mariátegui y Eduardo Galeano; pero sobre todo las citas que 
pertenecen a Héctor Velarde, Jorge Ibergüengoitia y Diego Maquieira, quienes aparecen en las páginas iniciales del libro, resultan reveladoras por el tono irónico con que abordan las historias de los países hispanoamericanos. Probablemente el primer epígrafe, que corresponde a Héctor Velarde, condense mejor el espíritu irónico y crítico del libro: "Los presidentes del Perú son siempre un poco incas y un poco virreyes. Si son muy incas, los peruanos de la corona los rechazan. Si son muy virreyes, los peruanos de las mascaipacha los rechazan. Si son muy democráticos, los peruanos de la corona y de la mascaipacha los rechazan como productos exóticos" (p. 15). En este epígrafe se pone humorísticamente en tela de juicio el espíritu democrático de los peruanos e incluso su propia identidad.

Otro elemento importante en los ensayos de Iwasaki corresponde a las notas al pie de página que suman en total 195. Esta recurrencia frecuente a las notas al pie de página sin duda le dan un carácter notorio de intertextualidad, es decir, los ensayos de Iwasaki entablan un diálogo con otros textos, ya sean históricos, literarios o filosóficos, los cuales al mismo tiempo le sirven para su argumentación.

El libro va acompañado además con una breve prólogo de carácter testimonial de su relación con la historia hispanoamericana, por ello recurre a una oposición semántica: realistasespañoles/utopistas-americanos, esto con el fin de explicar el proceso de la independencia, la cual a doscientos años aún continúa por ello se pregunta el autor: "¿Será que los utopistas continúan luchando contra los realistas?" (p. 19). En esta nota deja en claro que se trata de ensayos históricos pero con un estilo literario.

El libro lleva un epílogo al que el autor llama "Salida de emergencia" en el que sin dejar ese tono irónico, hace conclusiones generales sobre la historia latinoamericana que se pueden sintetizar en la siguiente expresión: "En realidad, políticamente hablando, españoles y latinoamericanos seguimos siendo hijos de nuestro patético siglo XIX, solo que en España los líderes modernos sueñan con escindirse en varios países, mientras que los nuevos líderes hispanoamericanos todavía sueñan con arrejuntarse bajo una sola bandera. Como se puede apreciar, realista no queda casi nadie" (p. 202).

En relación a cómo se presenta la ironía en el cuerpo mismo de los ensayos de Iwasaki es necesario destacar el uso de la hipérbole, figura que consiste en una ponderación exagerada de la realidad (Ayuso, García y Solano, 1990). Esta figura principalmente se manifiesta en el uso de adjetivos, adverbios y ciertos sustantivos que nos brindan una mirada desmesurada de la realidad, claramente con una intención crítica e irónica. Así, por ejemplo, en E7 encontramos: “No hay siglo más rocambolesco y peor aprovechado literariamente que nuestro aciago siglo XIX. Salpicado de cuartelazos, guerras oligofrénicas y estrambotes patrióticos, casi no hay país de América Latina que no haya incubado media docena de constituciones durante aquellos patéticos años [las cursivas son nuestras]" (p. 96), o más adelante en el mismo ensayo: "En realidad, el siglo XIX español fue tan patético y estrafalario como el de América Latina, pues transcurrió espurriado de sublevaciones y algaradas goriláceas [las cursivas son nuestras]" (p. 101).

Uno de los ensayos más irónicos sin duda es E5, "1812: Constitución original y pecado constitucional". Ya el mismo autor lo anuncia desde el inicio: "El título del presente capítulo quiere ser algo más que un juego de palabras, pues 
alude a una evidencia histórica que considero irrefutable [...] " (p. 71). Asimismo este ensayo tiene frecuentes alusiones sexuales, fisiológicas y psicoanalíticas cuando se refiere a asuntos jurídicos:

- "[...] la incontinencia constitucional que nos encalabrina a los pueblos hispanos desde que descubrimos la concupiscencia parlamentaria [las cursivas son nuestras]" (p.71).

- " $[\ldots]$ aquella incontinencia legislativa [las cursivas son nuestras] colapsó el gobierno de los últimos Asturias $[\ldots]^{\prime \prime}$ (p. 74).

- "Aquí fue donde Dionisio Inca Yupanqui decidió pedir la palabra, después de soportar más de dos semanas de empobrecedoras discusiones. ¿Cómo era eso de la inmoralidad que los negros mamaron [las cursivas son nuestras] con la leche? El primer argumento del diputado Inca Yupanqui fue lácteo [las cursivas son nuestras]" (p. 79).

- "En términos psicoanalíticos, las Cortes de Cádiz fueron la «escena primaria» de nuestra libido constitucional, y por eso las sociedades hispanas estamos persuadidas de que la mejor Constitución es la que se está por redactar. Y aquí mi conclusión también podría ser láctea: está en la leche que mamamos [las cursivas son nuestras]" (p.81).

Las enumeraciones también le atribuyen un sentido irónico a los ensayos. Así en E5 encontramos: " [...] de manera simultánea llegaron a estar vigentes los Fueros, las Siete Partidas, el Ordenamiento de Montalvo, las Leyes de Toro, las Leyes de Burgos, las Leyes Nuevas, la Nueva Recopilación de las Leyes de España y las Leyes de Indias (p. 74). Asimismo en E4: "[...] España descubrió el consumo del tabaco a través de los ingleses, descubrió el consumo del tomate gracias a los italianos, descubrió el consumo de la patata a través de los franceses y ahora mismo está descubriendo el consumo del maíz gracias a McDonald's" (p. 67).

\section{Nivel pragmático y crítico}

Una de las disciplinas que permite aproximarnos al terreno interdisciplinar del análisis del discurso es la pragmática. Esta se encarga de estudiar las intenciones comunicativas. Escandell Vidal señala que los elementos que figuran la situación comunicativa son de tipo material e inmaterial. En el primer caso, tenemos al emisor, el destinatario, el enunciado y el entorno; en el segundo, la información pragmática, la intención y la distancia social (1993, pp. 30-44). Veamos estos elementos en los ensayos de Iwasaki:

En relación al emisor, es la voz del mismo ensayista Fernando Iwasaki, que asume su condición de latinoamericano que reflexiona sobre España, y a la vez asume que es un español que mira América Latina; esta doble condición enriquece su análisis y visión de nuestra historia común. El destinatario está constituido por los lectores de sus ensayos, quienes no necesariamente deben ser especialistas en temas históricos; sin embargo, el libro de Iwasaki presupone un tipo de lector informado, o en términos de Roland Barthes, requiere de un lector modelo que coopere en la construcción del sentido del texto. Los enunciados funcionarían como macroenunciados los cuales están constituidos por cada uno de los doce ensayos del libro. El entorno y la información pragmática están constituidas por la situación espaciotemporal. Los espacios centrales que hace referencia Iwasaki son España y América Latina. Temporalmente, sus ensayos abarcan desde el siglo XVI, pero principalmente se enfoca en los siglos XIX y XX. Finalmente, sobre la intención 
pragmática, tratándose de ensayos de carácter histórico, podemos decir que en términos generales el autor pretende persuadir al lector de que tanto España como América Latina tenemos historias similares, y que muchos de los problemas que aún no hemos logrado resolver es precisamente porque todavía no nos hemos independizado del todo de España, no tenemos una identidad propia y arrastramos los defectos y virtudes de la península.

Por otro lado, una de las principales tareas de la pragmática es estudiar el uso del lenguaje en determinados contextos; asimismo dilucidar frente a qué tipo de discurso estamos y cómo es utilizado. En ese sentido, resulta válida la pregunta cuál es la diferencia formal entre un relato ficticio $y$ un relato no ficticio como la historia, ya que como vimos los ensayos históricos de Iwasaki presenta las estructuras sintácticosemántica y retórica o verbal de los relatos de ficción, entonces nos preguntamos qué hace que leamos estos textos como históricos y no como literarios, a pesar que el mismo autor señale: "Aunque la ambición de estos ensayos es histórica, el tono será más bien literario, a la manera de la Breve historia de Inglaterra de Chesterton y de los Momentos estelares de la humanidad de Stefan Zweig, porque si fuera cierto -como creía Marx- que la historia se repite la primera vez como tragedia y la segunda como farsa, a partir de la cuarta o quinta repetición tal vez solo nos quede la literatura" (p.19).

Es necesario señalar que el discurso histórico está imbuido de ficcionalidad por el componente narrativo y retórico que posee. El historiador Hyden White considera que gracias a la teoría literaria moderna el discurso histórico puede ser considerado como un "artefacto verbal, un producto de un tipo especial de uso de lenguaje" (2003, p.
147). Basándose en la clasificación de los principales tropos como la metáfora, la metonimia, la sinécdoque y la ironía, White establece cuatro tipos de discurso histórico según el tipo de trama: romance, tragedia, comedia y sátira.

Habiendo ya identificado la presencia de la ironía en los ensayos de Iwasaki en la sección del análisis verbal o retórico, en esta parte del análisis pragmático consideramos que Iwasaki ironiza la historia hispanoamericana situándose en el medio de los dos extremos descritos por White, es decir, de forma benigna sus ensayos tienden a desenmascarar humorísticamente las complejas y negativas secuelas que España ha heredado a las sociedades hispanoamericanas, tales como la religiosidad, el sistema político, el racismo, el caudillismo, etc.; en su forma más negativa, la visión que se desprende de Iwasaki es un profundo pesimismo por la realidad que vivimos en Hispanoamérica, tanto desde el punto de vista político, cultural, económico y social Así, por ejemplo, en E1, Iwasaki al reflexionar sobre la falta de modernidad de España y de las repúblicas nacientes, reclama que la mentalidad hispánica no concibe la compatibilidad entre igualdad y libertad: "De ahí que en todo el mundo hispánico exista una gran desconfianza hacia la libertad de elección, el libre mercado, la libertad de prensa, la economía libre, la libertad de cultos, el voto libre o hacia cualquier persona física o jurídica que vaya por libre, como si fuera un delito hacer algo diferente a lo impuesto por la mayoría."(p. 29). La falta de respeto a la libertad nos dice el ensayista "nos condenó al narcisismo botarate de las sociedades cerradas" (p. 30). Lo mismo pasa en E5, en las cortes de Cádiz se dejó de lado el principio de la igualdad al no otorgarles derechos a las castas. La ausencia de estos dos principios, igualdad y libertad, 
serían para el ensayista peruano las principales causas de una modernidad a medias de las sociedades hispanoamericanas.

El estilo irónico que utiliza Iwasaki en la casi totalidad de sus ensayos es expresión del pesimismo con que capta la realidad hispanoamericana en sus múltiples facetas. Quizá solo el último ensayo E 12, referido a la literatura hispanoamericana tiene un atisbo de optimismo en la medida que el ensayista cree que en el futuro "nadie hablará de literatura española y literatura hispanoamericana como si se tratara de dos literaturas incompatibles, sino de literatura comparada en español o literatura en español a secas" (p. 198). Es decir, la literatura lograría conjuncionar lo que por siglos la historia no ha podido hacer.

Este breve análisis pragmático que hemos realizado tiene que ir de la mano con el análisis crítico de la ensayística de Iwasaki, ya que es importante conocer cuál es la estructura ideológica que se desprende de sus textos.

Antes bien, es necesario reconocer que el ensayo ha desempeñado un papel importante en la conformación de la identidad cultural en América Latina desde que se fundaron los Estadosnación en nuestro continente. Así en el siglo XIX se convierte en el principal vehículo de la prédica de ideas, y en las primeras décadas del siglo XX se afianzó aún más este género discursivo con temática latinoamericanista y con visión netamente crítica. José Martí, José Enrique Rodó, José Carlos Mariátegui, Germán Arciniegas, etc., son pues algunos de los ensayistas que pensaron e interpretaron críticamente a Latinoamérica, y se constituyen en la base de cualquier aproximación moderna al estudio de Latinoamérica. Si bien, el ensayo, por su naturaleza, no es un discurso que requiere exhaustividad en el tratamiento del tema, a diferencia de un artículo científico o un tratado; sino que es un discurso que plantea una versión personal de un determinado tema, en este caso la realidad latinoamericana. En otras palabras, el ensayo es un discurso crítico por excelencia para pensar Latinoamérica, y más aún, el ensayo es el género fundacional de la modernidad al decir de unos críticos como Ignacio Sánchez Prado (2007, p. 304). El libro de Iwasaki se constituye en una crítica a la modernidad de Hispanoamérica.

Gran parte de la tradición ensayística latinoamericana precisamente tuvo como eje de preocupación el tema en torno a Hispanoamérica, su identidad e historia. Iwasaki en su libro Republicanos cuando dejamos de ser realistas parece retomar esa temática, pero con una visión y estilos diferentes, tal como lo hemos planteado en el análisis precedente.

Si hacemos un recuento temático de los doce ensayos de Iwasaki, los cuales forman un todo uniforme, vemos que para este ensayista desde el punto de vista histórico, económico, social, jurídico, político, religioso y cultural, los latinoamericanos no nos hemos independizado completamente de España, es decir, no hemos adquirido una identidad propia porque arrastramos los defectos y virtudes de la península y nunca hemos logrado consolidarnos como verdaderos Estados naciones. Basta traer a colación algunos ejemplos de aquellos vicios como el excesivo legalismo y falta de respeto a la ley de nuestras naciones que observa Iwasaki en sus ensayos como E5 donde aborda el tema de las cortes de Cádiz y su repercusión en el sistema constitucional hispanoamericano. Igualmente en E7 donde aborda el tema de la influencia negativa del caudillismo español en Latinoamérica, o en E9 donde reflexiona sobre el racismo 
presente en siglos en Hispanoamérica.

Considero que el discurso de Iwasaki sobre los países hispanoamericanos se inscribe dentro de la corriente crítica a la modernidad, y lo hace desde una postura liberal crítica, ya que incluso es crítico al mismo tiempo del propio liberalismo. Al ser España una nación carente de modernidad especialmente en el siglo XIX, necesariamente esto iba a influir en las nuevas repúblicas hispanoamericanas. Ya Iwasaki lo ha expresado en E1: "En realidad, la modernidad que echo en falta en España y América Latina durante el siglo XIX habría supuesto una actitud más respetuosa hacia la legalidad y las instituciones democráticas, una concepción laica del Estado y de la enseñanza pública, una separación real entre la estructura del Estado y los gobiernos detentados por los partidos políticos [...]" (p. 29). Todas estas debilidades señaladas por el ensayista peruano se extienden incluso hasta el siglo XXI en gran parte de las naciones hispanoamericanas.

Probablemente, la falta de modernidad que alude Iwasaki se expresa mejor en la idea de un proyecto de modernidad inconclusa. Si bien ha existido un discurso de la modernidad desde la Independencia política, esta modernidad nunca se dio como en las naciones de Occidente, sino que se priorizó la modernización económica, en desmedro de la modernización política y cultural, lo cual no han posibilitado que se desarrollen verdaderas democracias y han generado que se den contradicciones en las prácticas, así, por ejemplo, en el plano económico se puede ser muy liberal pero al mismo tiempo ser muy conservador desde el punto de vista cultural.

Iwasaki pareciera ser partidario de un programa cultural crítico de la modernidad para América Latina y la propia España que fortalezca a los ciudadanos y la sociedad civil para lograr que funcione realmente la democracia y desterrar de una vez el caudillismo, las dictaduras militares, los gobiernos mercantilistas que han desvirtuado al neoliberalismo, las prácticas nocivas como la discriminación y el racismo encubierto.

Por otro lado, Iwasaki también pareciera ser partidario de una identidad global más que local, ya que en E10, por ejemplo, cuestiona los sentimientos nacionalistas que se fomentaron en España y en América Latina, los cuales han servido sobre todo para segregar y discriminar al otro. Lo que sí deja en claro es que "una cosa es hablar de la cultura, las tradiciones e incluso del patrimonio lingüístico y literario de una comunidad, y otra muy distinta es la manipulación doctrinaria y programática que podría hacerse de todo aquel acervo en función de objetivos políticos a corto y mediano plazo" (p. 145).

En el caso particular de la literatura, el ensayista peruano a partir de su análisis del boom latinoamericano, y la emergencia del posboom con la emblemática figura de Roberto Bolaño, se muestra a favor del "nihilismo identitario, la abolición de las fronteras geográficas y filológicas y la necesidad individual de conquistar una autonomía literaria dentro de la República mundial de las Letras" (p. 197). En otras palabras, Iwasaki defiende una visión cosmopolita de la literatura sin que ello signifique su renuncia a su condición de escritor hispanoamericano.

Finalmente, podemos decir que al igual que muchos intelectuales liberales latinoamericanos como Octavio Paz, Mario Vargas Llosa o Carlos Fuentes, Fernando Iwasaki asume que el proyecto de modernidad en Hispanoamérica es inconcluso. Precisamente su libro de ensayos nos recuerda que el liberalismo 
económico, que lamentablemente ha devenido en un devastado mercantilismo, no ha promovido un liberalismo cultural y político ni ha garantizado las libertades individuales ni ha propiciado el surgimiento de sociedades democráticas, respetuosas del Estado de derecho. El resultado es que España y Latinoamérica siguen siendo espejos en los que ambas regiones pueden ver sus propias falencias: sociedades cerradas que necesitan abrirse, y precisamente Iwasaki aboga por ese liberalismo cultural y político, basados en la libertad y apertura intelectual, pero "ocurre que la libertad y la apertura intelectual no son del agrado ni de las culturas oficiales ni de los guardianes de las identidades nacionales $[\ldots]^{\prime \prime}$ (p. 203). Estas últimas palabras nos recuerdan el pesimismo irónico que recorre las páginas de este magnífico libro.

\section{CONCLUSIONES}

A través de este trabajo hemos querido demostrar que el libro de ensayos Republicanos cuando dejamos de ser realistas de Fernando Iwasaki, cuya temática general se centra en una reflexión predominantemente histórica sobre el Bicentenario de las Independencias de los países hispanoamericanos, entabla una relación intertextual entre el discurso histórico y el discurso literario a través de la ironía.

Desde el punto de vista sintácticosemántico y verbal, los ensayos históricos de Fernando Iwasaki presentan una estructura análoga a la estructura de los textos literarios, lo cual confirma lo que el historiador Hyden White plantea en torno a que el discurso histórico en realidad es un artefacto literario, ya que hace un uso especial del lenguaje. Desde el punto de vista pragmático y crítico, los ensayos de Iwasaki revelan un estilo irónico cargado de pesimismo sobre la realidad de las sociedades hispanoamericanas; asimismo, desde su postura liberal el autor considera que heredamos una mentalidad hispánica que aún no logra independizarnos del todo de España.

Finalmente, la ironía es un recurso literario necesario para reflexionar sobre procesos tan importantes de nuestra historia, ya que permite desenmascarar sutilmente profundas verdades que no nos permiten ver la realidad con claridad; por tanto, es un instrumento crítico por excelencia más aún si es empleado en el género ensayístico. Los ensayos de Fernando Iwasaki ironizan nuestra realidad, pero a la vez nos hacen comprenderla y cuestionarla.

\section{REFERENCIAS BIBLIOGRÁFICAS}

Adorno, T. (1962). Notas de literatura; tr. de Manuel Sacristán. Barcelona, España: Ariel.

Arenas, M. E. (1997). Hacia una teoría general del ensayo: construcción del texto ensayístico, Cuenca: Universidad de Castilla-La Mancha.

Aullón, P. (1984). El ensayo en los siglos XIX y XX. Madrid, España: Playor.

Ayuso, M., García, C. y Solano, S. (1990). Diccionario de términos literarios. Madrid, España: Akal.

Broeck, S. Van Den (2010). Ironía y transnacionalismo en España aparta de mi estos premios de Fernando Iwasaki, Leuven, en:

http://www.cervantesvirtual.com /obra/ironia-y-transnacionalismoen-espana-aparta-de-mi-estospremios-de-fernando-iwasaki/

Díaz, W. (2010). El ensayo: estructura y propósito. Arequipa, Perú: Apóstrofe.

Falla, R. (1992). Frondas peruanas: Salinas, 
León Pinelo, Meléndez -inicios del discurso ensayístico-. Lima, Perú: UNMSM.

Gómez-Martínez, J. L. (1992). Teoría del ensayo. México: UNAM.

Iwasaki, F. (2008). Republicanos cuando dejamos de ser realistas. Madrid, España: Algaba.

Jaimes, H. (2001). La reescritura de la historia en el ensayo hispanoamericano. Madrid, España: Fundamentos.

Maíz, C. (2004). El ensayo: entre género y discurso. Debate sobre el origen y funciones en Hispanoamérica. Mendoza, Argentina: Facultad de Filosofía y Letras de la Universidad Nacional de Cuyo.

Mignolo, W. (2007). La idea de América Latina. Barcelona, España: Gedisa.

Neira, H. (2008). Teoría y práctica del ensayo. Lima, Perú:Siklos.
Oviedo, J. M. Breve historia del ensayo hispanoamericano. Madrid, España: Alianza editorial.

Schoentjes, P. (2003). La poética de la ironía. Madrid, España: Cátedra.

Sánchez, I. (2007). El arte de la ironía: Carlos Monsiváis ante la crítica. México: Era.

Skirius, J. (1989). El ensayo hispanoamericano del siglo XX. México: FCE.

Weinberg, L. (2004). Umbrales del ensayo. México: UNAM.

Weinberg, L. (2006). Situación del ensayo. México: CCYDELUNAM.

Weinberg, L. (2007). Pensar el ensayo. México: siglo XXI.

White, H. (1992). Metahistoria, La imaginación histórica en la Europa del siglo XIX. México: FCE.

White, H. (2003). Teoría literaria y escrito histórico, en El texto histórico como artefacto literario. Barcelona, España: Paidós. 